\title{
POR UM ESPAÇO PÚBLICO LAICO: OS atentados ao Charlie Hebdo E ALGUMAS REPERCUSSÕES NO BRASIL
} Youssef Cherem ${ }^{1}$

O debate incitado recentemente pelo artigo de Demétrio Magnolli², e as esperadas, mornas e repetitivas respostas de Williams Gonçalves ${ }^{3}$ e Arlene Clemesha ${ }^{4}$ evidenciam mais uma vez o estado de coisas em que se encontra parte da academia brasileira e sua posição (ou falta dela) a respeito de assuntos que, convenhamos, têm um apelo marginal entre os intelectuais brasileiros. Novamente analistas se utilizam dos mesmos argumentos para explicar o terrorismo.

Uma parte das críticas ao jornal Charlie Hebdo se refere ao seu apelo a uma linguagem cáustica, de seu humor debochado, e, o que de pouco se tem falado senão indiretamente, de sua visualidade. Plínio Zúnica ${ }^{5}$ afirmou, em um artigo intitulado "Por que não sou Charlie Hebdo": "Não é assim que se levanta um debate, não é assim que se dialoga e não é assim que se contesta." A frase se referia à imagem do Charlie Hebdo em que um de seus editores aparece beijando Maomé, com uma placa: "O amor é mais forte que o ódio". Ora, afirmar que não se pode contestar nenhuma crença através de desenhos ou outra forma de arte, e que tudo deveria ser feito através de debates públicos e pela palavra escrita, não tem qualquer respaldo na própria tradição de debate público ocidental, desde o início da imprensa e antes. Revistas especificamente humorísticas e satíricas, com forte carga visual, têm longa história, como demonstra a

\footnotetext{
1 Professor de História da Arte Islâmica, Universidade Federal de São Paulo. Doutor e mestre em Antropologia Social pela UNICAMP; bacharel em Relações Internacionais pela PUC-MG.

2 http://www1.folha.uol.com.br/colunas/demetriomagnoli/2015/01/1573138-raqqa-aqui.shtml.

3 http://www1.folha.uol.com.br/opiniao/2015/01/1575784-williams-goncalves-resposta-a-demetriomagnoli.shtml.

convivencia.shtml.

http://www1.folha.uol.com.br/opiniao/2015/01/1575748-arlene-clemesha-a-opcao-pela-

5 http://operamundi.uol.com.br/conteudo/opiniao/39106/por+que+nao+sou+charlie+hebdo++je+ne+suis+pas+charlie.shtml.
} 
revista inglesa Punch, surgida em 1841. A crítica social através de imagens só pode ser negada justamente com o argumento de Zúnica - que implica, axiomaticamente, que imagens não podem ser um argumento. Em vez de interpretar e discutir uma evidência visual de uma figura (as capas do Charlie), toma-se como ponto de partida sua ilegitimidade. Dispensa-se, assim, qualquer trabalho semiótico, qualquer análise propriamente dita das charges, porque, por definição, elas não deveriam existir.

Outras vezes, afirma-se ser desrespeitoso qualquer representação de Maomé, porque a religião islâmica proibiria isso taxativamente. Embora certas correntes salafistas realmente tenham como preceito a interdição estrita da representação artística de seres animados (animais, seres humanos, djins, anjos) em todos os contextos, logo percebe-se que há representações visuais históricas e/ou religiosas de Maomé pelo menos desde o século XIII. ${ }^{6}$

Aí chegamos ao segundo argumento: essas figuras não deveriam existir porque seriam "racistas". A lógica é a seguinte: a) grande parte dos imigrantes franceses são muçulmanos e árabes, sendo que a maior parte dos muçulmanos de nacionalidade francesa são seus descendentes; b) a maioria dos excluídos social e economicamente na sociedade francesa é composta justamente desses muçulmanos; c) consequentemente, pois que dirigida a uma população em situação de "fragilidade" (social, econômica, política, cultural etc.), essa sátira é desigual, reforçando a imagem de inferioridade desses grupos. Os cristãos, judeus e outros grupos de direita e esquerda aguentam a sátira; os muçulmanos, não. Uma consequência desse argumento é que se explica, quase que por um automatismo sociológico, por que esses jovens "excluídos", membros de um grupo inferior em todos os sentidos, poderiam desenvolver um ódio contra a sociedade majoritária circundante. Esse tipo de explicação comete o equívoco de assumir um imediatismo causal entre uma situação percebida como injusta e atitudes violentas supostamente decorrentes dessa situação. É uma variante da corrente que tenta explicar o terrorismo como consequência da pobreza - o que nunca explicaria por que um filho de magnata como Bin Laden, um médico como Zawahiri e um ex-traficante como Zarqawi utilizam a mesma estratégia (embora Zarqawi e seus asseclas, assim como o Estado Islâmico, tenham uma abordagem mais facínora, inclemente e brutal do terrorismo e da implementação de um governo islâmico). Essa explicação sócio-

\footnotetext{
${ }^{6}$ GRUBER, C. Between Logos (Kalima) and Light (Nur): Representations of the Prophet Muhammad in
} Islamic Painting. Muqarnas 26, 2009, 1-34. 
econômica ignora a explicação dos próprios autores para seus atos, atribuindo essa explicação a algo como uma "falsa consciência", porque a explicação seria de fundo, econômico-social, estrutural. Mas esse argumento parte do pressuposto de conceber como amálgama uma realidade social multifacetada. Uma religião não é o mesmo que uma raça, uma etnia, uma língua, uma cultura. Dizer que uma sátira a uma crença equivale a racismo e xenofobia não é um mero deslize semântico - é a mesma coisa que igualar "árabes" a "muçulmanos". É o erro inverso dos que consideram os cristãos no Oriente Médio como uma "quinta coluna" do "imperialismo" ocidental, como oportunistas, de lealdade e moralidade duvidosa.

Através da explicação estrutural, o que deveria ser um mero contexto (a falta de integração de uma minoria religiosa/étnica/econômica facilitaria a infiltração de ideologias extremistas) se torna a única explicação possível e causa necessária e suficiente para o surgimento do fenômeno. Mas, mesmo supondo que o diagnóstico estrutural seja acertado, o elo entre a estrutura e a ação dos indivíduos ou grupos não é de forma alguma explicitado ou analisado. Assim, as explicações correntes sobre os atentados são postas de lado em favor de uma hipotética explicação alternativa que nunca é apresentada, em que a explicação sócio-econômica dá as mãos à "crítica geopolítica", por assim dizer: é culpa do "orientalismo", do imperialismo, da potência que age (violando a soberania) ou que deixa de agir (respeitando a soberania), que apoia ditadores (fazendo com que a oposição seja majoritariamente religiosa) ou que apoia a oposição religiosa contra esses mesmos ditadores. Uma hora os EUA são culpados por apoiar Mubarak; logo em seguida, por não fazer nada contra ele; e depois, são culpados por "apoiar" (ou respeitar) a eleição de Morsi. São explicações rasteiras e contraditórias que ignoram a dinâmica de poder e a estrutura normativa que rege a política internacional. $\mathrm{O}$ ato terrorista seria resultado de uma conjunção de opressão interna e opressão internacional. (Obviamente isso não explicaria o terrorismo sectário do Iraque, vários outros casos, mas isso é devidamente ignorado nessa análise.)

Essa posição é evidenciada pelo prof. Salem Nasser ${ }^{7}$, que afirma que a responsabilidade dos atentados de Paris é "da França": "responsabilidade que resulta do passado colonial e que faz da França devedora em relação às antigas colônias, em relação aos imigrantes e em relação aos franceses descendentes de imigrantes.” Nasser ainda afirma: "Praticamente todas as análises e todos os comentários partem de uma

\footnotetext{
${ }^{7}$ http://paulomoreiraleite.com/2015/01/20/responsabilidades-francesas/.
} 
presunção: a de que se conhece a autoria do atentado e, em seguida, de que se conhece [sic] os objetivos perseguidos pelos responsáveis. Essa presunção parte de premissas que sempre deveriam ser postas em dúvida." Em seguida, Nasser nega todas as análises (identidade e objetivos dos executores do ato) mas não apresenta nenhuma interpretação alternativa, a não ser a volta da "responsabilização" ao passado colonial e a atual política internacional. Isso é ecoado na resposta de Williams Gonçalves ${ }^{8}$ à crítica de Magnolli: "Há alta tensão na França porque o governo socialista de François Hollande apoia integralmente a iniciativa dos Estados Unidos de suprimir o Estado Islâmico, bem como também promoveu intervenções militares no Mali e na República Centro Africana." O que é evidência dessa "alta tensão" não é nunca explicitado, exceto ex post facto pelos atentados, num raciocínio circular. Mas, se tudo fosse culpa do passado colonial, veríamos terroristas vietnamitas, camaroneses e malgaxes manifestando seu rancor; veríamos violência provocada como represália às intervenções francesas na África. Mas não foi isso que ocorreu.

Talvez seja hora de levar a sério as explicações ideológicas para o extremismo islâmico; de levar mais a sério as explicações dos próprios perpetradores dos atentados, da rede transnacional de financiamento, aliciamento e treinamento. Esses fatores fazem parte necessária e indissociável de uma conjunção de elementos que tornam possíveis atos como esses, como os atentados de Madri, Londres, Nova Iorque etc. A constituição de grupos terroristas que financiam, recrutam membros, e fazem propaganda em todos os continentes não pode ser dissociada de sua ideologia, que é uma expressão de um programa supremacista calcado numa versão ao mesmo tempo política, social e teológica da religião islâmica. Nesse sentido, deve ser deixada de lado a discussão vazia entre os que defendem que o "terrorismo não é islâmico" e os que afirmam que "existe uma clara base na religião islâmica" para o terrorismo e o extremismo. A não ser que se creia que os terroristas e radicais islâmicos em geral mentem ao explicar suas ações por meio de uma ligação conceitual ao islamismo (e a não ser que se apresente uma outra hipótese mais verossímil além da assunção de "falsa consciência", e da "falsa religião"), temos que partir do seu próprio discurso. Temos que admitir, com franqueza e destemor (o que não é fácil nos dias de hoje, haja vista o clima de intimidação prevalecente), que é possível derivar, conceitualmente, a ideologia político-teológica islamista de tradições 8 http://www1.folha.uol.com.br/opiniao/2015/01/1575784-williams-goncalves-resposta-a-demetrio-
magnoli.shtml. 
islâmicas textuais e históricas. E que existem vários grupos direta ou indiretamente relacionados entre si que promovem essa ideologia através da propaganda, da força, da intimidação e do terrorismo.

Negar a ligação concreta entre elementos da tradição islâmica a ideologia que os radicais propagam é negar a história e distorcer a realidade com o intuito de se apresentar politicamente correto. É apresentar um verniz pacifista ao conceito de jihad que não tem fundamento histórico (jihad "defensiva", jihad como "luta espiritual") - um viés que foi sempre minoritário no pensamento político e teológico islâmico. Isso leva a afirmações desprovidas de sentido, seja de um lado, seja de outro do debate sobre o tema que vemos instaurado atualmente no Brasil. Por um lado, vemos Magnolli ${ }^{9}$ afirmar: "Atribuir ao Islã a responsabilidade pelo jihadismo é mais ou menos como culpar o romantismo alemão pelas atrocidades do nazismo. Os soldados rasos da jihad na Europa chegaram ao jihadismo diretamente, sem a intermediação do Islã" (grifo nosso). Ora, o jihadismo não existiria sem o islamismo; senão, teria outro nome. Ser um mujahid (guerreiro da jihad) "sem intermediação do Islã" é algo que não faz o menor sentido. Magnolli ainda sugere que a relação que a ideologia do terrorista norueguês Anders Behring Breivik tem com o cristianismo seria a mesma que os terroristas dos recentes atentados de Paris teriam com o islamismo: Magnolli supõe que, da mesma forma como Breivik não foi chamado de um "terrorista cristão", também não podemos chamar os islamistas de "terroristas islâmicos", ignorando tanto o fato de que a) Breivik se considerava um "cristão cultural" e não religioso e b) ele não poderia derivar sua ideologia diretamente do cristianismo. Já os islamistas acreditam piamente na mensagem de Maomé e sua tradição, e podem derivar sua ideologia diretamente deles.

A posição de Clemesha nesse sentido evidencia um desconhecimento fundamental das fontes islâmicas tradicionais, da jurisprudência islâmica, dos hadith (tradições orais sobre Maomé) e das biografias tradicionais do profeta do islamismo. Ela afirma que "não há qualquer pena para a blasfêmia no Corão, indicando-se apenas a necessidade de afastamento (não se sentar à mesa)." Não somente professora não cita fonte nenhuma para sua afirmação, como também se esqueceu que o islamismo como sistema de crenças só pode ser compreendido se interpretarmos o Alcorão à luz da sunna e dos hadith de Maomé: por exemplo, não há pena para consumo de álcool no Alcorão; o Alcorão também não estipula com exatidão as cinco orações diárias, entre

\footnotetext{
${ }^{9}$ http://oglobo.globo.com/opiniao/sao-islamicos-os-terroristas-15054894\#ixzz3S6NlOCo1.
} 
várias outras estipulações do islamismo: tudo isso só é explicado na biografia do Profeta e nos hadith, sem os quais, de fato, é impossível compreender o Alcorão. Ela também não cita a doutrina da ab-rogação, segundo a qual versículos posteriores (revelados em Medina, quando Maomé era politicamente forte) anulam versículos anteriores, mais tolerantes (revelados quando Maomé estava em Meca). Assim é que o versículo 9:29 "Lutai contra os que não acreditam em Deus nem no dia do julgamento e não proíbem o que Deus e seu apóstolo proibiram e não praticam a religião verdadeira entre os que foram dados um livro [judeus e cristãos] até que paguem tributo [jizya] de suas próprias mãos, e sejam humilhados." - é interpretado como anulando mais de 100 versos mais tolerantes e compreensivos para com os infiéis (por exemplo, no influente Tafsir (comentário do Alcorão) de Ibn Kathir, do séc. XIV).

\section{O livro Kitab Ash-shifa bi Ta'rif Huquq al-Mustafa (O Livro da Cura pelo} Reconhecimento das Verdades/Direitos do Escolhido [Maomé]), de Qadi Ayad (m. séc. XII), inclui uma seção intitulada: "A prova da necessidade de matar qualquer um que insulte o Profeta ou ache algum defeito nele", em que uma série enorme de sábios islâmicos é citada para provar a necessidade do assassinato de qualquer um que insulte Maomé. ${ }^{10}$

A afirmação de Clemesha oportunamente ignora correntes muçulmanas que afirmam que a blasfêmia equivale à apostasia (em todas as escolas de direito islâmico tradicionais, a apostasia é punível com morte); que a blasfêmia e o insulto ao Profeta são puníveis com a morte (malikitas e xiitas); e não menciona eventos da vida de Maomé em que ele consentiu, autorizou ou ordenou o assassinato de pessoas que o tratavam com escárnio, através de poesias ou discursos. Ela convenientemente deixa de lado implementações contemporâneas nas leis dos países muçulmanos onde blasfêmia e apostasia são crimes: uma pesquisa indica que, entre os países que proíbem ou punem legalmente a mudança de religião ("apostasia”), todos são muçulmanos ${ }^{11}$. No Oriente Médio, só Turquia, Líbano e Israel não têm lei contra a conversão.

Com todas essas evidências, como é que se pode desejar, como Clemesha, que os próprios muçulmanos impeçam outros muçulmanos de seguir essa linha argumentativa, e isso com o objetivo de "conciliar as liberdades de manifestação do pensamento e religiosa"? Ainda que seja uma expectativa louvável (eu espero sinceramente que os

\footnotetext{
${ }^{10}$ Tradução inglesa em: http://www.masud.co.uk/ISLAM/misc/alshifa/pt4ch1sec2.htm.

11 http://www.pewforum.org/2012/11/21/laws-penalizing-blasphemy-apostasy-and-defamation-ofreligion-are-widespread/.
} 
muçulmanos lidem teologicamente com seus próprios radicais), temos que admitir que isso é dificílimo, e que os muçulmanos só têm essas duas liberdades (de pensamento e religião) em países onde haja algum tipo de segurança física e jurídica que garanta essa liberdade de expressão. A resposta para essa garantia está na existência de um espaço público laico, e de leis que garantam a liberdade dos indivíduos nesse espaço.

A religião islâmica, no espaço público ocidental, está no mesmo patamar de todas as outras crenças, seja a wicca, a umbanda ou o paganismo greco-romano. No espaço público dos países regidos pela tradição ocidental do Estado de direito e de laicismo, Maomé vale tanto quanto Jesus Cristo ou Buda. O que muitos muçulmanos não conseguem aceitar é justamente isso: que Maomé, num espaço público laico, não é sagrado, embora possa sê-lo para muitos cidadãos que fazem parte desse espaço público. Eu posso não crer em Maomé, Jesus Cristo, Buda, Joseph Smith, e manifestar publicamente isso; eu posso não acreditar na shari'a, e tenho o direito de não ser julgado por uma lei religiosa na qual eu não acredito. O respeito exigido não é pela figura religiosa ou crença, é pela liberdade de outrem de seguir tal figura. Um indivíduo deve ter o direito de declarar que Maomé, Odin, Ganesha ou Iemanjá são falsos, e de desenhar essas figuras por brincadeira, por arte, ou para uma ilustração de um livro de história. Os muçulmanos não têm exclusividade do direito de se sentir ofendidos, não mais do que cristãos também têm o direito de se sentir ofendidos com uma obra como "Piss Christ", de 1987, em que uma cruz é mergulhada em urina. Mas o artista, Andres Serrano, continua vivo. 